\title{
Progressive Collapse of RC Box Girder Bridges due to Seismic Actions
}

\author{
Heba A. Mohamed ${ }^{1},{ }^{1}$ M. M. Husain, ${ }^{1}$ and Ayman M. Aboraya $\mathbb{D i D}^{2}$ \\ ${ }^{1}$ Structural Engineering Department, Faculty of Engineering, Zagazig University, Zagazig 44519, Egypt \\ ${ }^{2}$ Construction and Building Department, High Institute of Engineering, October 6th City, Giza 12592, Egypt
}

Correspondence should be addressed to Heba A. Mohamed; hebawahbe@yahoo.com

Received 30 January 2020; Revised 21 August 2020; Accepted 10 September 2020; Published 23 September 2020

Academic Editor: Hui Yao

Copyright $\odot 2020$ Heba A. Mohamed et al. This is an open access article distributed under the Creative Commons Attribution License, which permits unrestricted use, distribution, and reproduction in any medium, provided the original work is properly cited.

\begin{abstract}
Most of the recent studies focus on the progressive collapse of ordinary structures due to gravity and blast loads. A few focus on studying progressive collapse due to seismic actions, especially of bridge structures. The past major earthquakes have shown that it is possible to develop improved earthquake-resistant design techniques for new bridges if the process of damage from initial failure to ultimate collapse and its effects on structural failure mechanisms could be analyzed and monitored. This paper presents a simulation and analysis of bridge progressive collapse behavior during seismic actions using the Applied Element Method (AEM) which can take into account the separation of structural components resulted from fracture failure and falling debris contact or impact forces. Simple, continuous, and monolithic bridges' superstructures were numerically analyzed under the influence of the severe ground motions not considering the live loads. The parameters studied were the superstructure redundancy and the effect of severe ground motion such as Kobe, Chi-Chi, and Northridge ground motions on different bridge structural systems. The effect of reducing the reinforcement ratio on the collapse behavior of $\mathrm{RC}$ box girders and the variation of columns height were also studied. The results showed that monolithic bridge models with reduced reinforcement to the minimum reinforcement according to ECP 203/2018 showed a collapse behavior under the effect of severe seismic ground motions. However, changing the bridge structural system from monolithic to continuous or simple on bearing bridge models could prevent the bridge models from collapse.
\end{abstract}

\section{Introduction}

Progressive collapse phenomenon is defined as the global damage or collapse behavior of a large part of the structural system that is caused by a failure of a relatively small or localized part of the structure. Structural progressive collapse occurs as a result of failure of one or more structural members or components. The load is transferred in the structural system due to changes in the distribution of stiffness, the pattern of the stress behavior, and/or the structural boundary conditions [1]. This initial failure results in other structural elements being further overloaded and later fail. Studies on the progressive collapse of existing structures have focused primarily on high impact as in blasting or irregular loading. Not so much attention is paid to the vulnerability of structures, especially bridges, with regard to progressive collapse during earthquakes [2].

Seible et al. [3] noted that earthquake loads could result in progressive collapse of bridges influenced by earthquake characteristics such as magnitude, strength, source mechanism, and intensity. This phenomenon is noted during seismic events as with the Northridge and Kobe earthquakes. Continuous vibration after initial failure and repeated stress reversals from cyclic nonlinear behavior can lead to a significant degradation in the stiffness strength of the structural system. There would be a ductility capacity reduction due to cumulative damage effects in the dynamic structural behavior and response during major earthquakes.

Previous studies on the progressive collapse of structures gave insights into the effect of strengthening on improving 
the structural capacity to prevent progressive collapse due to seismic and blast loads. Those studies have shown that such detailing and strengthening against the earthquake could enhance buildings' progressive collapse resistance to such load effects $[4,5]$. Gurley [6] commented that improving a structure's ductility through reinforcement details could help improve its progressive mechanism of collapse. Given these results, there is still a lack of information on the progressive collapse and the mechanism of collapse that can be used to enhance the seismic design of new bridges and to establish more successful methodologies for strengthening and retrofitting old bridges.

Wibowo et al. [7] studied the seismic progressive collapse of RC bridges during earthquakes. They modeled only a continuous bridge that was previously experimented with "Guedes, 1997" [8]. The results have shown a good agreement. The separation of structural components resulting from fracture failure and impact forces from falling debris had been taken into consideration. The results have shown a significant influence on the performance of bridges during major earthquakes that were visible in its progressive collapse analysis. These also demonstrate the need to include progressive failure mechanisms in the assessment of seismic design efficiency and bridge evaluation that would not only lead to a better and more robust earthquake-resistant design for new structures but also more efficient retrofitting and reinforcement strategies for older structures.

In a similar vein, Salem et al. [9] analyzed numerically the collapse of Tsuyagawa Bridge damaged by the Tohoku Tsunami in March 2011. The Tohoku Tsunami swept across Japan's eastern coast, killing over 15,000 people and listing missing over 2,500 . The tsunami caused more than 400,000 buildings to collapse and more than 250 coastal bridges to be washed away. The analysis showed accurately the collapse behavior of the bridge, showing that the bridge collapsed at a water velocity of $6.6 \mathrm{~m} / \mathrm{s}$ caused by its piers' flexural failure. Tsuyagawa Bridge's AEM analysis has shown the ability to simulate the 2011 Tohoku Tsunami collapse effectively, although the analytical results showed less ductility when compared to reality.

Domaneschi et al. [10] analyzed numerically the collapse of the viaduct over the Polcevera Valley in Genoa that collapsed in August 2018. This incident left 43 deaths and several injuries caused by a collapse of a portion of the highway connection. The results of the analysis showed that the stay cable was the most important item whose failure caused the collapse. Furthermore, the simulation model indicated that the main girder triggered the collapse, and the large visible displacements involved in their collapse would have warned the authorities of the impending fault.

Bridges could be in several structural forms, i.e., simple on bearings, continuous on bearings, and monolithic with column bridge structures. There are no sufficient studies on the effect of severe seismic ground motions for such different bridges' structural systems; especially, most researchers studied bridges' models, either continuous or simple bridges. In the current study, Wibowo's Bridge is modeled and verified using the applied element method. Also, the effect of the reduction in reinforcement quantity on the collapse of
RC box girder bridges under Kobe ground motion is investigated. Several bridges' models with different structural systems such as simple on bearings, continuous on bearings, and monolithic with column bridges are analyzed under severe seismic ground motions: Kobe, Chi-Chi, and Northridge earthquakes.

\section{Applied Element Method}

The Extreme Loading for Structures (ELS) program, developed by ASI-2018 [11], is based on the AEM, which was initially developed by Tagel-Din and Meguro $[12,13]$ at the University of Tokyo in 1998 to solve problems related to two-dimensional plane stresses. It was later expanded to solve three-dimensional problems. The AEM is a novel method of modeling that adopts the discrete cracking concept in AEM. Structures are modeled as an element assembly. The elements are not rigid and connected by normal and shear springs along their joint surfaces. These springs are responsible for normal and shear stresses transfer between adjacent elements. Each spring represents a certain volume of material stresses and deformations (see Figure 1). Once the connecting springs fail, each of the two adjacent elements can be completely separated. The AEM adopts fully nonlinear path-dependent material constitutive models. AEM is a stiffness-based approach in which an overall stiffness matrix is formulated and equilibrium equations for each of the stiffness, mass, and damping matrices for structural deformations (displacements and rotations) are nonlinearly solved. The equilibrium equation solution is an implicit one that takes step-by-step dynamic integration (Newmark-beta time integration procedure) [14, 15]. If the springs connecting the elements are ruptured, two adjacent elements are separated from each other. Elements may separate, recontact, or contact other elements automatically depending on the structural response (see Figure 2).

\section{Material Models}

3.1. Modeling Concrete and Reinforcing Steel. Maekawa and Okamura's model [16] is used for concrete in compression, whereas for concrete in tension, the linear stress-strain relationship is adopted. In this stage, concrete is exposed to tension up to cracking where the stresses are set to zero afterward. Furthermore, for concrete in shear, a linear relationship between shear stresses and strain is assumed before the cracking. After cracking, a drop in the value of shear stresses to zero takes place [17]. Springs are also used to define the reinforcement between elements. Ristic's model [18] is used to model the reinforcement. Newmark- $\beta$ approach is used to solve equations of dynamics. The equilibrium equations are indeed linear for each step and are generally solved, in AEM, by using a direct or an iterative solver (Figure 1).

3.2. Bridge Bearing Material. An interface material is used to model bearings. The interface material model is a precracked element where the material is initially cracked and cannot bear tensile stresses. As for compression, the stress-strain 

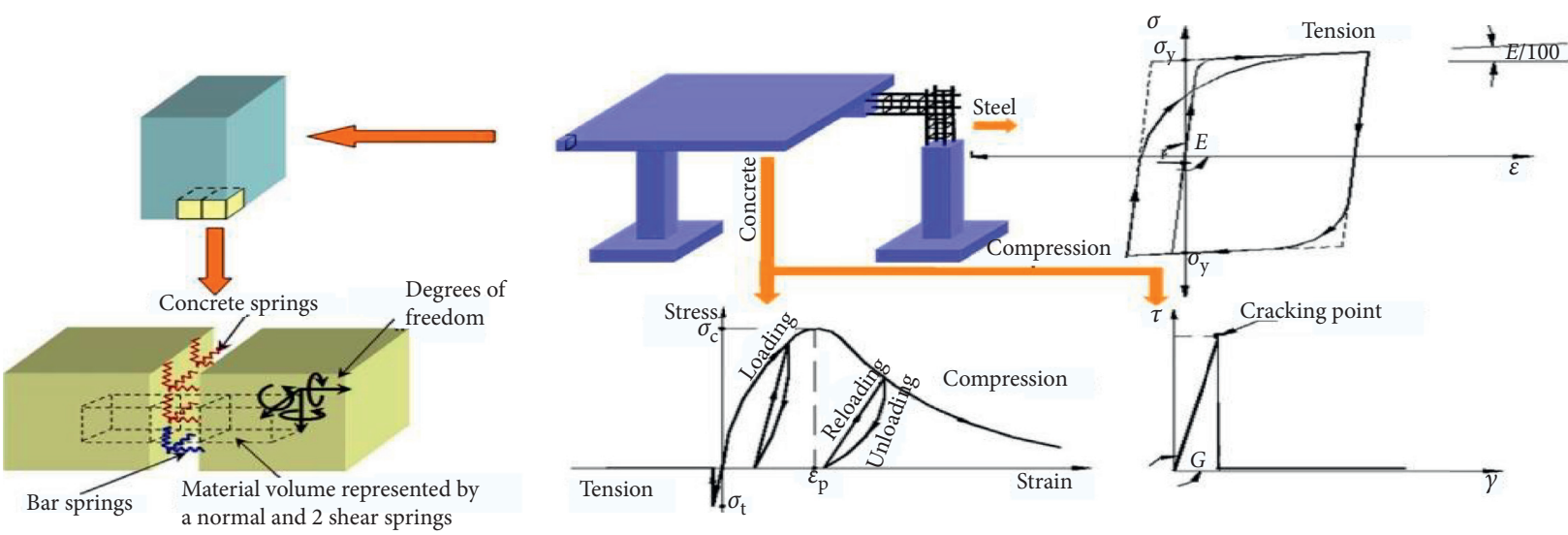

FIgUre 1: Modeling of a structure with AEM [9].

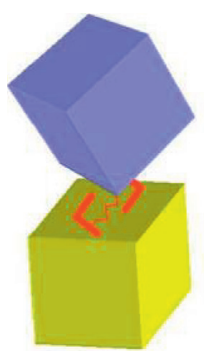

Shear spring in $y$

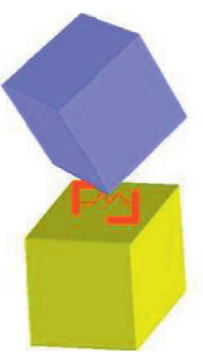

Shear spring in $X$

(a)

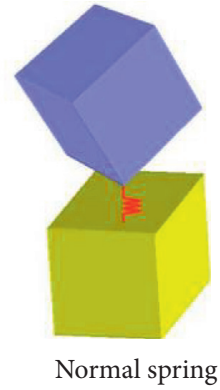

Normal spring

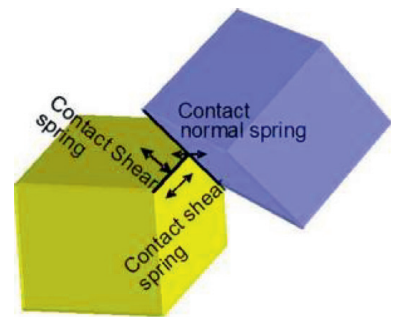

(b)

Figure 2: Different types of element contacts. (a) Corner-to-face or corner-to-ground contact. (b) Edge-to-edge contact [9].

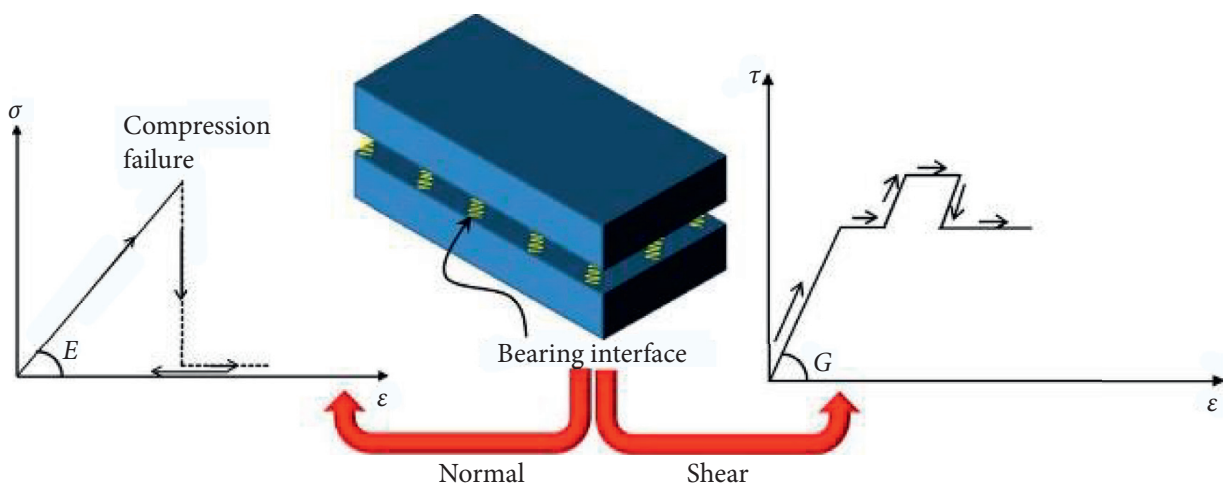

FIgure 3: Modeling of a bearing interface with AEM [9].

relation is linear up to compression failure stress (Figure 3). The relationship between shear stress and shear strain is linear until the shear stress approaches $\mu \sigma n$ (coefficient of normal friction $\times$ normal stress). At this stress level, the shear stress remains the value $(\mu \sigma n)$ as long as there is no change in normal stresses. The compressive stress variation allows the proportional variation in shear stresses $(\mu \sigma n)$. The shear stiffness is set as a minimum, if the crack opens or during active sliding of the bearing (see Figure 3 [9]).

\section{Comparison of AEM and FEM}

During progressive collapse analysis, the failure, separation, contact, and falling debris of elements must be traced. Using FEM, it is very difficult to model progressive collapse. On the other hand, using AEM, to analyze these processes is made easy and effective taking into consideration all the analysis stages until collision (Figure 4). 


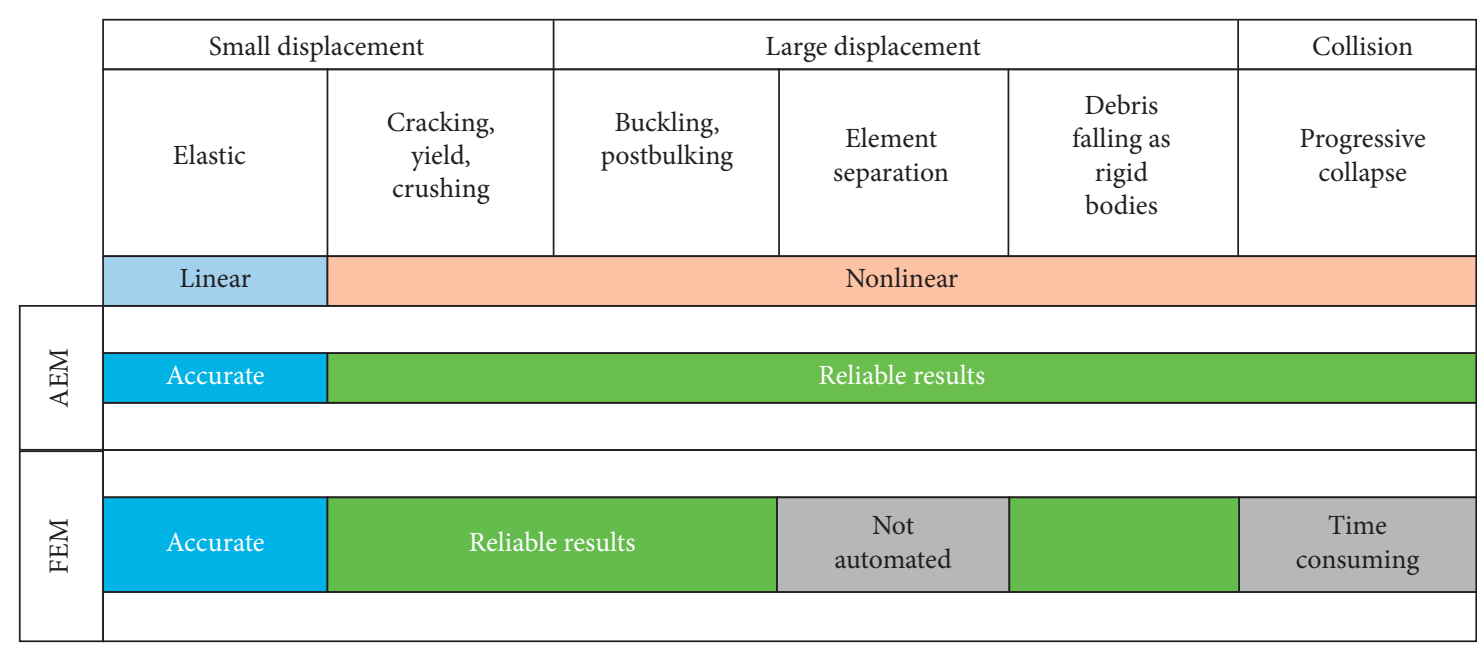

FIgURE 4: Scope of FEM and AEM.

\section{Verification}

5.1. Numerical Study. The selected numerical example was previously investigated experimentally by Guedes [8] and numerically by Wibowo et al. [7]. The bridge has four $20 \mathrm{~m}$ spans. The bridge deck is a hollow box girder, which has $5.6 \mathrm{~m}$ wide. The bridge has two end abutments at points 1 and 5 and has three piers at points 2, 3, and 5. The pier heights are shown in Figure 4. The piers are fixed at bottom base and the abutments are hinged at points 1 and 5. The connection between piers and the bridge box girder is hinged. The cross section of the bridge piers is a rectangular hollow-core RC section (Figure 5). The longitudinal reinforcement details of the box girder were maintained from Wibowo et al. ([7], see Figure 6). The material properties are also summarized in Table 1.

5.2. Artificial Earthquake Ground Acceleration. The used earthquake ground motion was artificial; it followed the work of Guedes [8]. Also, the mentioned artificial ground motion is previously used by Chiara and Rui [19], Lau and Wibowo [20], and Seyedkhoei et al. [21]. The peak ground acceleration (PGA) was $1.05 \mathrm{~g}$. Based on the estimated bridge design capacity, the PGA is increased by 1.2. The total time used for the analysis from the artificial earthquake record is 4 seconds, and it is applied in the transverse direction (Figure 7).

Hereby, the analysis is performed twice. The first assumes that the box girder is elastic, and the piers are assumed to be nonlinear, while the second considers the nonlinear behavior of the box girder and the piers. The top displacement of the piers is compared by that obtained from Wibowo et al. [7].

As shown in Figure 8, in the linear model, the average difference percentage of the current study and Guedes [8] was $7.87 \%, 4.2 \%$, and $4.6 \%$ for short, medium, and long piers, respectively. It was found out that the studied model could follow the response of the bridge piers with high precision. Also, the peak displacements of the piers that took place at the time of 3 to $3.5 \mathrm{~s}$ were identically obtained.
Analyzing the nonlinear model, the top displacements of the piers were compared by those obtained by Wibowo et al. [7] (see Figure 9). It was found out that the displacements were similar to a good degree. The difference in the displacements between the two models could be originated as the diameters of transverse reinforcement were not clearly mentioned by Wibowo et al. [7]. This can have a major effect on the difference with the current model.

Throughout the analysis of the nonlinear model, the collapse mechanism was monitored (Figure 10). Firstly, the box girder cracked at bridge abutments and then cracked at the locations of the piers because of the redistribution of the deck's own weight on the piers. Subsequently, the bridge deck showed shear failure because of punching on the bearing supports. Finally, the bridge deck progressively collapsed.

Through these results, it can be concluded that ELS can correctly model the bridge linear and nonlinear behavior, including various structural elements such as piers, bridge superstructure, reinforcement details, and material properties, and thus can provide reliable results.

\section{Bridge Models}

6.1. Bridge Layout. RC box girder bridges were modeled $3 \times 25000$ millimeters bays (Figure 11). Various bridge configurations were studied; the bridge superstructures are monolithic box girder with columns, continuous box girder on bearings, and simple box girder on bearings. The columns were assumed to be fixed at its bases. The bridge superstructure was rested on elastomeric bearing plates. Each row of the bearing contained five elastomeric bearings. The bridge dimensions and reinforcement details were originally taken from executed multispan box girder bridges in Egypt. The damping ratio is assumed to be $5 \%$ during the analysis. The analyzed bridge models and the reinforcement of the box girders are shown in Figure 12 and Table 2. The purpose of analyzing models A1-M-K, A2-M-K, and A3-M-K (Table 2) was to determine the reinforcement reduction effect on the collapse behavior during the dynamic seismic 


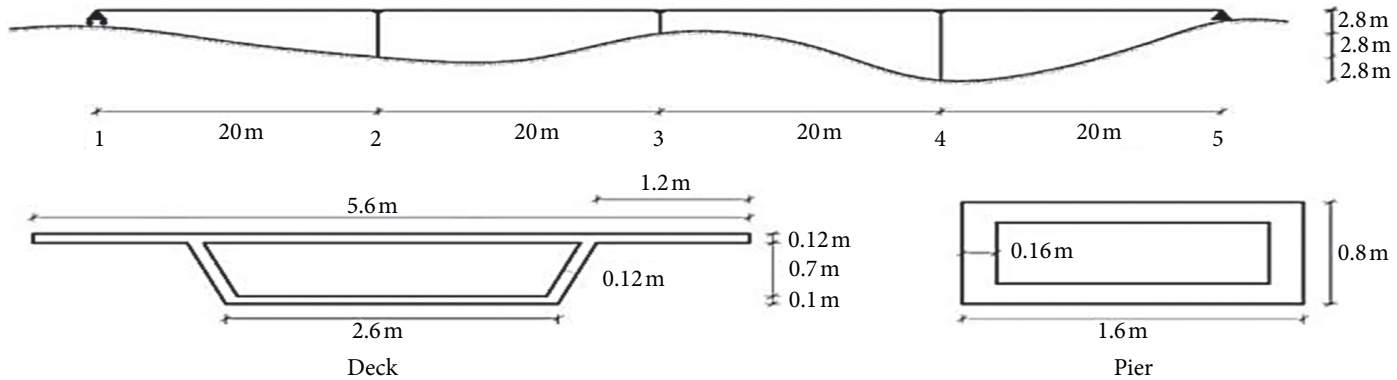

Figure 5: Layout of the bridge structural elements [7].

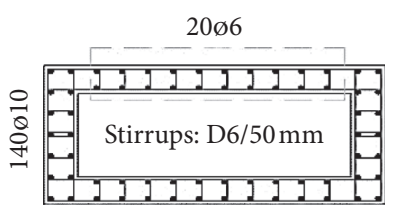

(a)

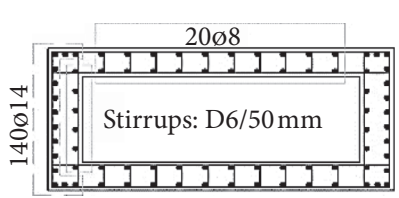

(b)

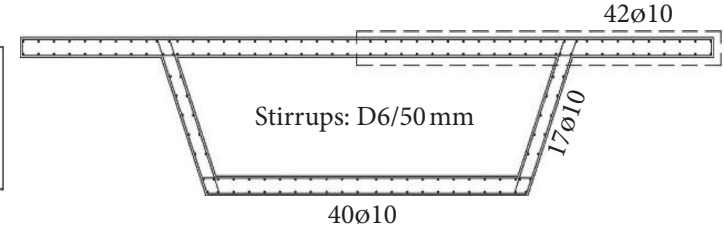

(c)

Figure 6: Reinforcement details of the numerical study [7].

TABLE 1: Material properties of the numerical model.

\begin{tabular}{|c|c|c|c|c|c|c|}
\hline Parameter & Pier 2 & Pier 3 & Pier 4 & Box girder & R. Steel & Unit \\
\hline Compressive strength & $3.212 e 06$ & $3.569 e 06$ & $4.375 e 06$ & $3 e 06$ & $3.6 e 07$ & $\mathrm{~kg} / \mathrm{m}^{2}$ \\
\hline Tensile strength & $3.212 e 05$ & $3.569 e 05$ & $4.375 e 05$ & $3 e 05$ & $3.6 e 07$ & $\mathrm{~kg} / \mathrm{m}^{2}$ \\
\hline Strain at unconfined peak stress & 0.002 & 0.002 & 0.002 & 0.002 & - & $\mathrm{m} / \mathrm{m}$ \\
\hline Young's modulus & $2.55 e 09$ & $2.55 e 09$ & $2.55 e 09$ & $2.55 e 09$ & $2.0389 e 09$ & $\mathrm{~kg} / \mathrm{m}^{2}$ \\
\hline Shear modulus & $1.062 e 09$ & $1.062 e 09$ & $1.062 e 09$ & $1.062 e 09$ & $8.155 e 09$ & $\mathrm{~kg} / \mathrm{m}^{2}$ \\
\hline Specific weight & 2549.291 & 2549.291 & 2549.291 & 2549.291 & 7840 & $\mathrm{~kg} / \mathrm{m}^{3}$ \\
\hline Separation strain & 0.1 & 0.1 & 0.1 & 0.1 & 0.2 & - \\
\hline Friction coefficient & 0.8 & 0.8 & 0.8 & 0.8 & 0.8 & - \\
\hline Postyield stiffness ratio & - & - & - & - & 0.01 & - \\
\hline
\end{tabular}

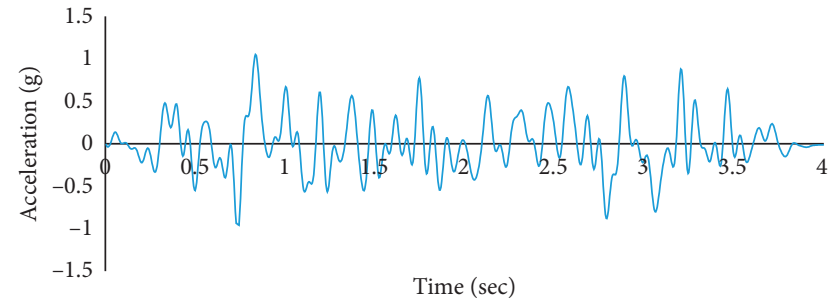

Figure 7: Artificial earthquake ground motion [7].

loading. In models $\mathrm{A} 3-\mathrm{C}-\mathrm{K}$ and $\mathrm{A} 3-\mathrm{S}-\mathrm{K}$ (Table 2), the structural system of the bridge superstructures was changed from the monolithic to simple box girder on bearings and continuous on bearings, respectively. The behavior of such systems was compared with that of the monolithic bridge. Also, a comparison between simple, continuous, and monolithic bridge models was carried out under severe ground motions, i.e., Kobe, Chi-Chi, and Northridge.

6.2. Material Properties. The material properties adopted in AEM analysis are presented in Table 3. A full bond was assumed between the concrete and the reinforcing steel. The used bearing was composed of a top and bottom steel plates and bearing material in between as in Salem et al.'s work [9]. The dimensions of the steel plates used were $500 \times 500 \times 50 \mathrm{~mm}$. The dimension of the elastomeric bearing interface was assumed to be $350 \times 350 \times 130 \mathrm{~mm}$ [22]. The interface between the steel plates was given bearing material properties[9]. A relatively high compressive strength was given to the bearing interface so it could not fail in compression and act linearly [23]. The shear modulus of the bearing was assumed to be $2 \mathrm{MPa}[22,24]$.

\section{Ground Acceleration}

Kobe, Chi-Chi, and Northridge ground accelerations were used in the progressive collapse analysis of the bridge models, as there was some bridge collapse during these earthquakes [25]-[29]. The ground motions data was obtained from the Pacific Earthquake Engineering Research (PEER), Strong Motion Database [30]. A summary of the earthquake ground motions used in this research is presented in Table 4 and is shown in Figure 13. The time used in the seismic analysis was reduced to the time that contains the largest cycles of seismic accelerations to reduce the ELS analysis time, as the time that would not 


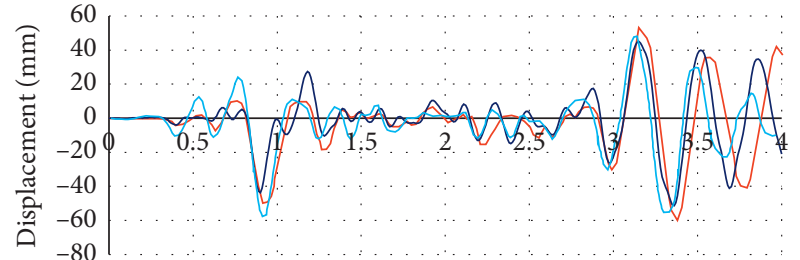

Time (sec)

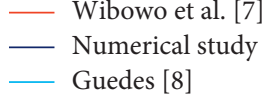

(a)

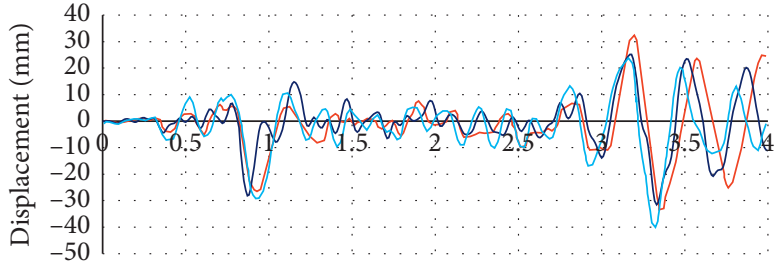

Time (sec)

- Wibowo et al. [7]

- Numerical study Guedes [8]

(b)

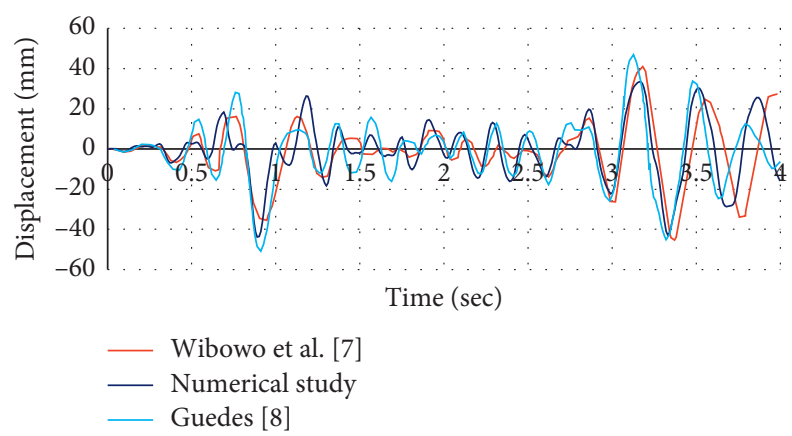

(c)

Figure 8: Comparison between the displacement time history of the top end of the piers of the numerical study and the research of Wibowo et al. [7] and Guedes [8] (linear box girder). (a) Short pier. (b) Medium pier. (c) Tall pier.

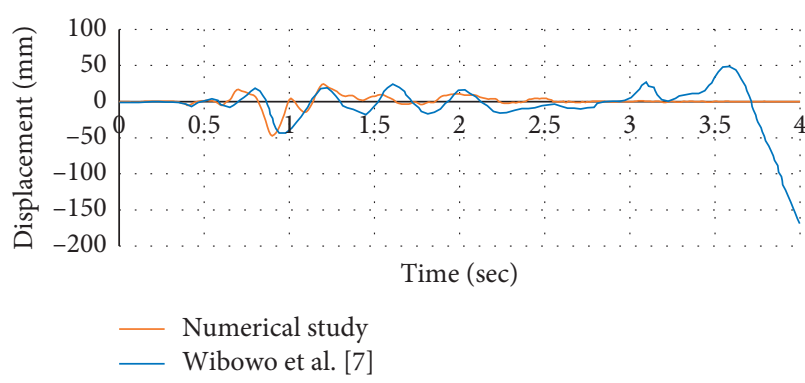

(a)

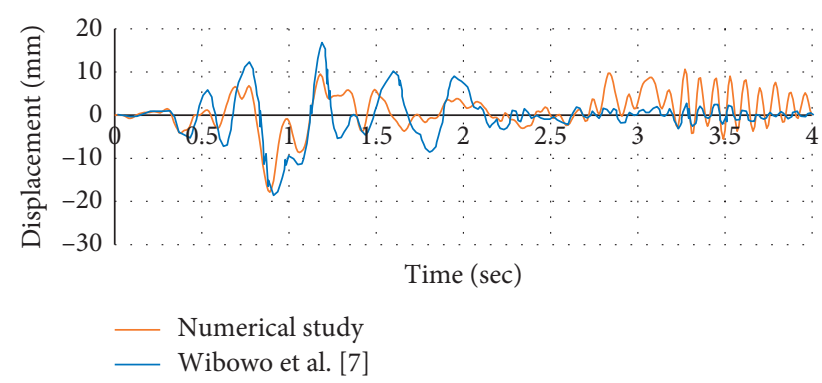

(b)

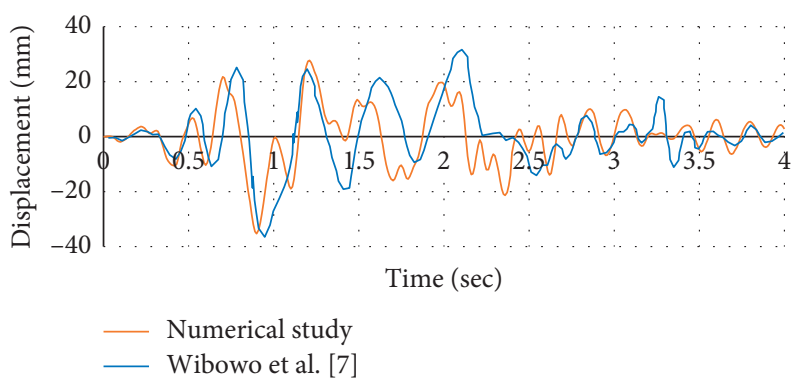

(c)

FIGURE 9: Comparison between the displacement time history of the top end of the piers of the numerical study and the research of Wibowo et al. [7] (nonlinear box girder). (a) Short pier. (b) Medium pier. (c) Tall pier.

contain significant values of acceleration could be omitted. The used time step during the analysis was 0.004 . Earthquake analysis usually requires $\Delta$ of $0.001-0.01 \mathrm{sec}$. when a collision is expected to occur. The smaller the time step is, the higher the accuracy and the convergence of results becomes. 


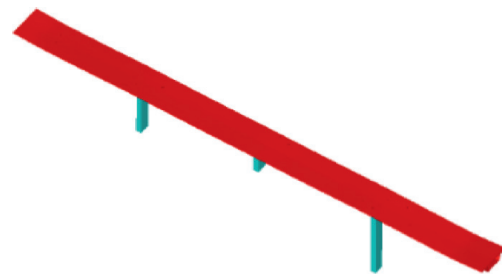

1.50

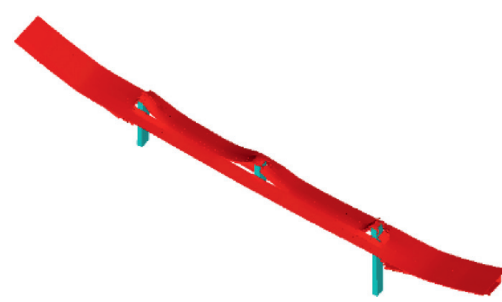

2.75

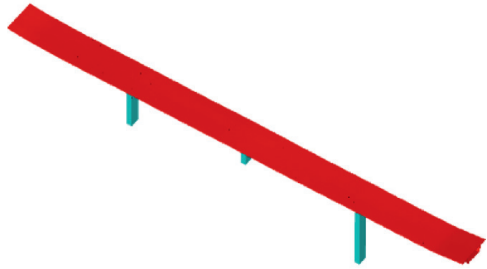

2.10

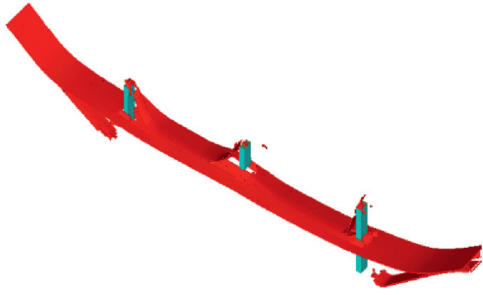

3.22

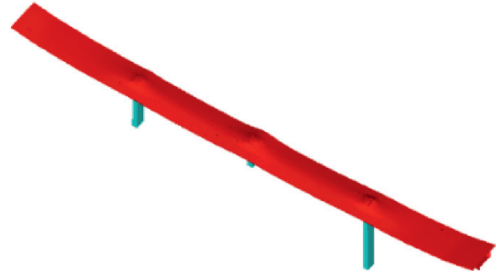

2.42

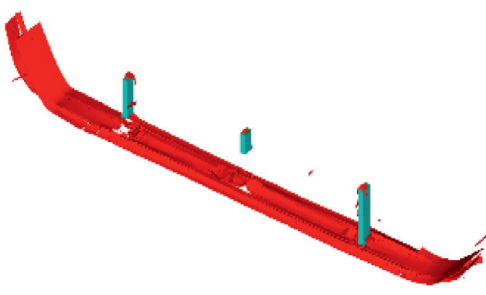

4.00

FIGURE 10: Collapse mechanism of the nonlinear bridge model during the time history.

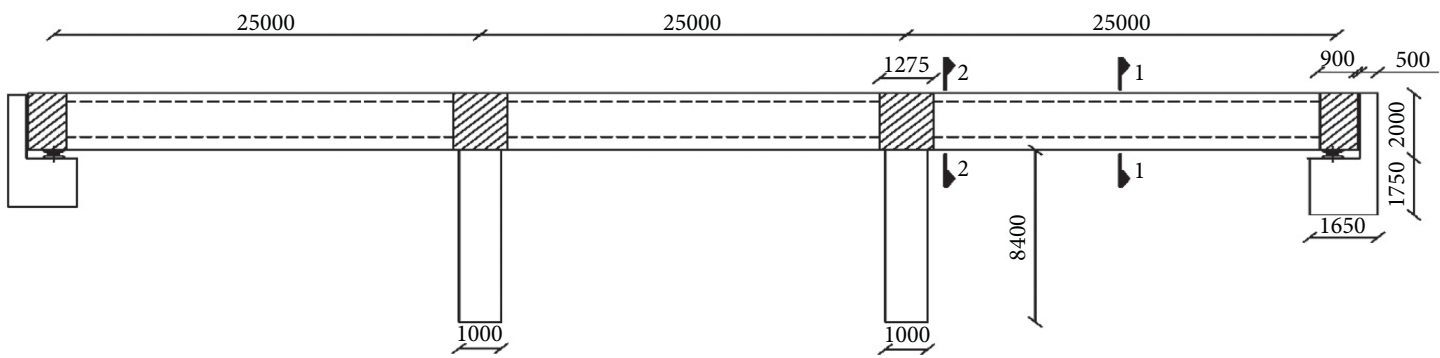

(a)

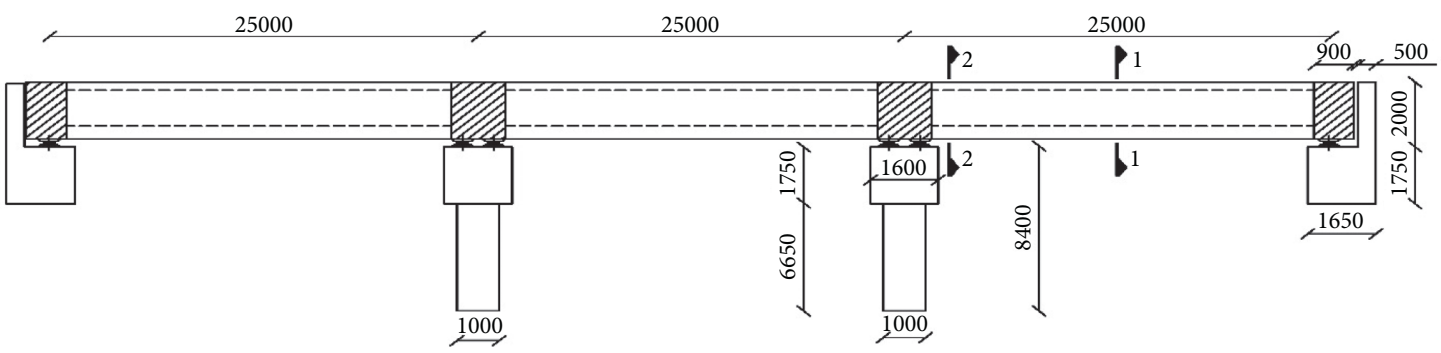

(b)

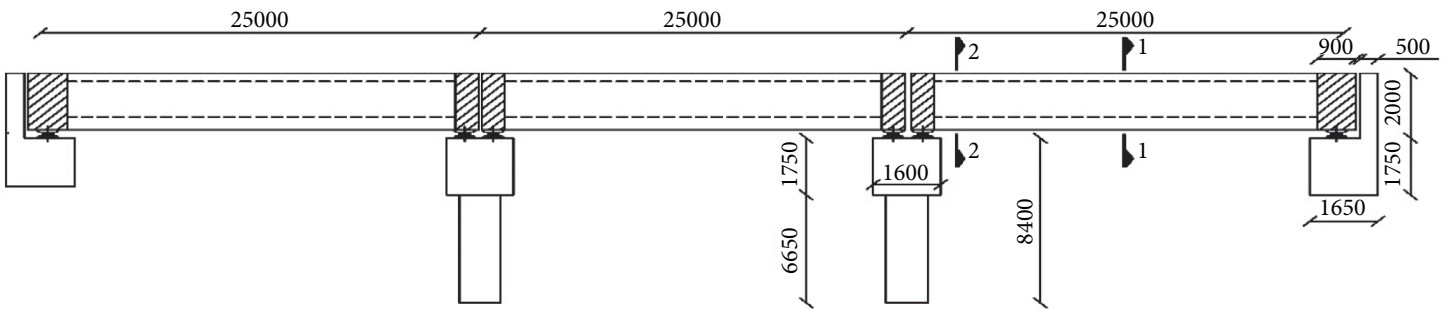

(c)

FIGURE 11: Layout of the box girder bridges. (a) Monolithic with columns; (b) continuous on bearing; and (c) simple box girder bridges on bearing.

\section{Mesh Sensitivity Analysis}

A mesh sensitivity analysis was carried out to obtain a suitable mesh size that would be used in all the analysis cases for columns and bridge superstructure. Horizontal and vertical concentrated loads were used for the column and the box girder, respectively. Figure 14 shows the relationship between the mesh elements and the displacement of the column and the deflection of the box girder. 22 elements per column's height and $5 \times 12$ elements per columns' cross section were used. The maximum dimensions for the columns' elements were $200 \times 200 \mathrm{~mm}$ per element cross 


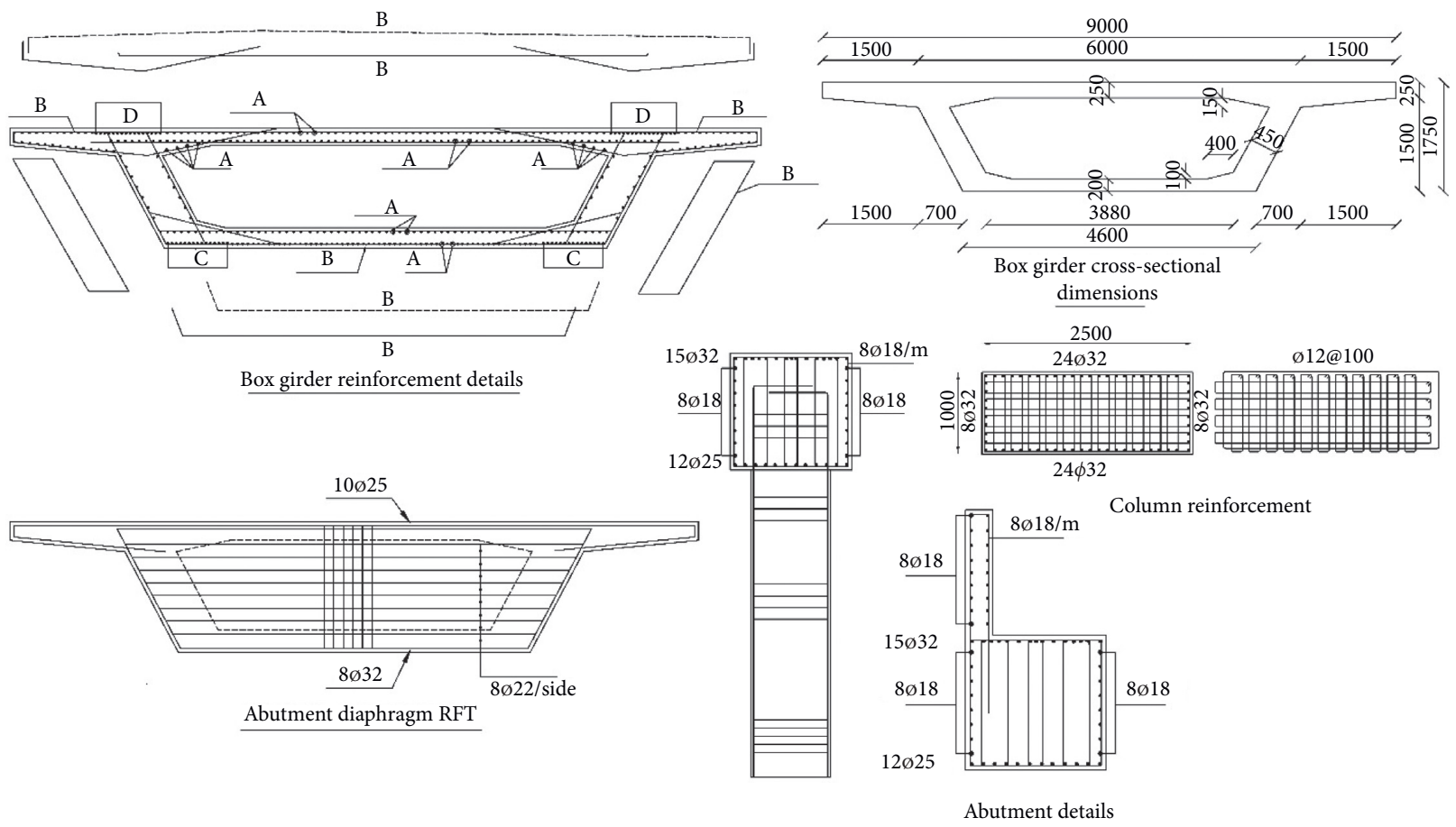

FIGURE 12: Dimensions of the box girder and reinforcement details of the bridge elements.

TABLE 2: Bridge models and box girder reinforcements (unit: $\mathrm{mm}$ ).

\begin{tabular}{|c|c|c|c|c|c|c|c|c|}
\hline \multirow{3}{*}{$\begin{array}{l}\text { Model } \\
\text { A1-M-K }\end{array}$} & \multirow{3}{*}{$\begin{array}{c}\text { Ground motion } \\
\text { Kobe }\end{array}$} & \multirow{3}{*}{$\begin{array}{l}\text { Bridge system } \\
\text { Monolithic }\end{array}$} & \multicolumn{5}{|c|}{ Reinforcement of the box girder } & \multirow[b]{2}{*}{ Reinforcement ratio (\%) } \\
\hline & & & Sec. & \multicolumn{2}{|c|}{$\begin{array}{c}\varnothing(\mathrm{mm}) / \mathrm{spacing} \\
(\mathrm{mm})\end{array}$} & \multicolumn{2}{|c|}{$\begin{array}{c}C \quad D \\
\text { No. of bars } \varnothing \\
(\mathrm{mm})\end{array}$} & \\
\hline & & & $\begin{array}{l}1 \\
2\end{array}$ & $\varnothing 16 / 125$ & $\varnothing 18 / 125$ & $16 \varnothing 32$ & $\begin{array}{l}10 \emptyset 32 \\
34 \emptyset 32\end{array}$ & 100 \\
\hline A2-M-K & Kobe & Monolithic & $\begin{array}{l}1 \\
2\end{array}$ & $\varnothing 10 / 125$ & $\varnothing 10 / 125$ & $16 \varnothing 18$ & $\begin{array}{l}10 \emptyset 18 \\
34 \varnothing 18\end{array}$ & 35 \\
\hline A3-M-K & Kobe & & 1 & & & & $10 \varnothing 16$ & \\
\hline A3-M-C & Chi-Chi & Monolithic & & $\varnothing 10 / 125$ & $\varnothing 8 / 125$ & $16 \varnothing 16$ & & \\
\hline A3-M-N & Northridge & & 2 & & & & $34 \varnothing 16$ & \\
\hline A3-C-K & Kobe & & 1 & & & & $10 \varnothing 16$ & \\
\hline A3-C-C & Chi-Chi & Continuous & & $\varnothing 10 / 125$ & $\varnothing 8 / 125$ & $16 \varnothing 16$ & & 25 \\
\hline A3-C-N & Northridge & & 2 & & & & $34 \varnothing 16$ & \\
\hline A3-S-K & Kobe & & & & & & & \\
\hline A3-S-C & Chi-Chi & Simple & 1 & $\varnothing 10 / 125$ & $\varnothing 8 / 125$ & $30 \varnothing 16$ & $10 \varnothing 16$ & \\
\hline A3-S-N & Northridge & & & & & & & \\
\hline
\end{tabular}

$*-\mathrm{M}-*$ : monolithic; $*-\mathrm{C}-*$ : continuous; and $*-\mathrm{S}-*$ simple bridges. $*-*-\mathrm{C}$ : Chi-Chi; $*-*-\mathrm{K}$ : Kobe; and $*-*-\mathrm{N}$ : Northridge.

section and was $38 \mathrm{~cm}$ per element height. Each surface area of the box girder (i.e., the deck, soffit, and webs) was divided into $5 \times 1$ elements with 50 elements per 25 m length (span) in the box girders' longitudinal direction. This mesh size was found to give accurate results. An analysis using a finer mesh has been carried out without any noticeable difference in the displacement and deformation. The total number of elements used for monolithic, continuous, and simple bridges was $10,000,13,800$, and 13,200, respectively. The AEM mesh used was accurate enough during the elastic region and in the small deformation range of the inelastic region $[12,13]$.

\section{Analysis Results}

The analysis was carried out on two stages; the first was static to take into account the gravity loads and original deformations of the bridge, whereas the second was a dynamic analysis, implementing the different seismic ground 
TABle 3: Properties of the bridge materials.

\begin{tabular}{|c|c|c|c|c|}
\hline Parameter & Concrete & Steel reinforcement and plates & Bearing interface & Unit \\
\hline Compressive strength & $4 e 06$ & $3.6 e 07$ & $5.51 e+07$ & $\mathrm{~kg} / \mathrm{m}^{2}$ \\
\hline Tensile strength & $4 e 05$ & $3.6 e 07$ & - & $\mathrm{kg} / \mathrm{m}^{2}$ \\
\hline Young's modulus & $2.213 e 09$ & $2.0389 e+09$ & $2.0389 e+09$ & $\mathrm{~kg} / \mathrm{m}^{2}$ \\
\hline Shear modulus & $984297 e 03$ & $8.1556 e+09$ & 203943 & $\mathrm{~kg} / \mathrm{m}^{2}$ \\
\hline Specific weight & 2500 & 7840 & 7840 & $\mathrm{~kg} / \mathrm{m}^{3}$ \\
\hline Separation strain & 0.2 & 0.12 & 1 & - \\
\hline Friction coefficient & 0.8 & 0.8 & 0.6 & - \\
\hline Ultimate strength/tensile stress & - & 1.4444 & - & - \\
\hline Normal contact stiffness factor & 0.0001 & 0.0001 & 0.0001 & - \\
\hline Shear contact stiffness factor & $1.00 e-05$ & $1.00 e-05$ & $1.00 e-05$ & - \\
\hline Contact spring unloading stiffness factor & 2 & 2 & 2 & - \\
\hline Postyield stiffness ratio & - & 0.01 & - & - \\
\hline
\end{tabular}

TABLe 4: Seismic ground motions.

\begin{tabular}{lcccccc}
\hline Earthquake & Year of occurrence & Record station & PGA in X-Dir. (g) & Moment magnitude & Original duration & Reduced duration \\
\hline Kobe & Jan 1995 & KJMA & 0.834 & 6.9 & 90 & 20 \\
Chi-Chi & Sep 1999 & CWB & 0.63 & 7.6 & 90 & 15 \\
Northridge & Jan 1994 & CDMG & 1.585 & 6.7 & 40 & 15 \\
\hline
\end{tabular}

motions. For more details about how the analysis was carried out, please refer to ELS theoretical manual, ASI [11]. The principal strain of the bridge models was used to analyze crack locations and collapse patterns.

9.1. Reinforcement Reduction Effect. Figure 15 shows the displacement time history for the right column of A1-M-K, A2-M-K, and A3-M-K models. The three models showed a relatively identical behavior, as the reduction in the reinforcement ratio did not produce any failure in the structural elements to the analysis termination. Once the reinforcement ratio is reduced to $25 \%$, the box girder of model A3-MK collapsed; it showed a deviation in the displacement-time history. The right bay of the bridge box girder started to collapse. And once it hit the ground, the column exhibited large displacement. The right column maximum horizontal displacement for the three models before failure was $200 \mathrm{~mm}$. It was extended further to $300 \mathrm{~mm}$ after failure in model A3-M-K.

Figure 16 shows the straining actions. The straining actions of A1-M-K, A2-M-K, and A3-M-K models were nearly identical excluding model A3-M-K. Model A3-M-K showed a deviation at the 8 th second as the right bay of the bridge box girder showed cracks, and it developed further to collapse. Once the collapse initiated, the $50 \%$ reduction in the axial column load occurred. Other straining actions behavior for the same model showed a nonuniform behavior to the end of the analysis. The maximum magnitude of moment and shear during the time history analysis was $1250 \mathrm{~m} \cdot$ ton and -350 tons, respectively.

9.2. Effect of Kobe Ground Motion on Different Bridge Structural Configurations. Figure 17 shows the displacement-time history of the right column of the bridge's different configurations. Displacement time history of models A3-M-K, A3-C-K, and A3-S-K was identical. However, after the failure of the bridge box girder of the monolithic model at the 15 th second, the displacement curve showed a deviation from the other models to the end of the analysis. The maximum displacement amplitudes were measured at the 5th second and equal 300, 275, and $200 \mathrm{~mm}$ for simple, continuous, and monolithic bridge models, respectively. The simple and continuous models showed large displacement amplitudes, while the monolithic bridge models showed a less displacement amplitude. This could be attributed to the rigid connection between the bridge superstructure of the monolithic bridge and the columns, as it resisted the displacement movement of the bridge superstructure. The less the internal restrains in the bridge are, the more increase in displacements takes place.

Figure 18 shows a comparison between the straining actions of monolithic with columns, continuous on bearings, and simple on bearings bridge models. As mentioned before, the monolithic bridge model, A3-M-K, showed a collapse behavior. However, when analyzing simple and continuous models, A3-S-K, and A3-C-K, it was found out that the displacements are similar and they did not show any collapse behavior to the end of the analysis.

9.3. Collapse Analysis of Different Bridge Models during Kobe Ground Motion. Cracks are represented through the principal strains. A comparison between models A1-M-K, A2$\mathrm{M}-\mathrm{K}$, and $\mathrm{A} 3-\mathrm{M}-\mathrm{K}$ is presented in Figures 19-21, respectively. The less the bridge superstructure reinforcement, the more cracks or collapse observed in the box girder. At the end of the analysis time, A1-M-K and A2-M-K did not collapse. Reinforcement reduction beyond the minimum reinforcement ratio, model $\mathrm{A} 3-\mathrm{M}-\mathrm{K}$ according to the ECP203-2018 [31], allowed the bridge model to show a collapse behavior. At failure initiation after 4 seconds, the 


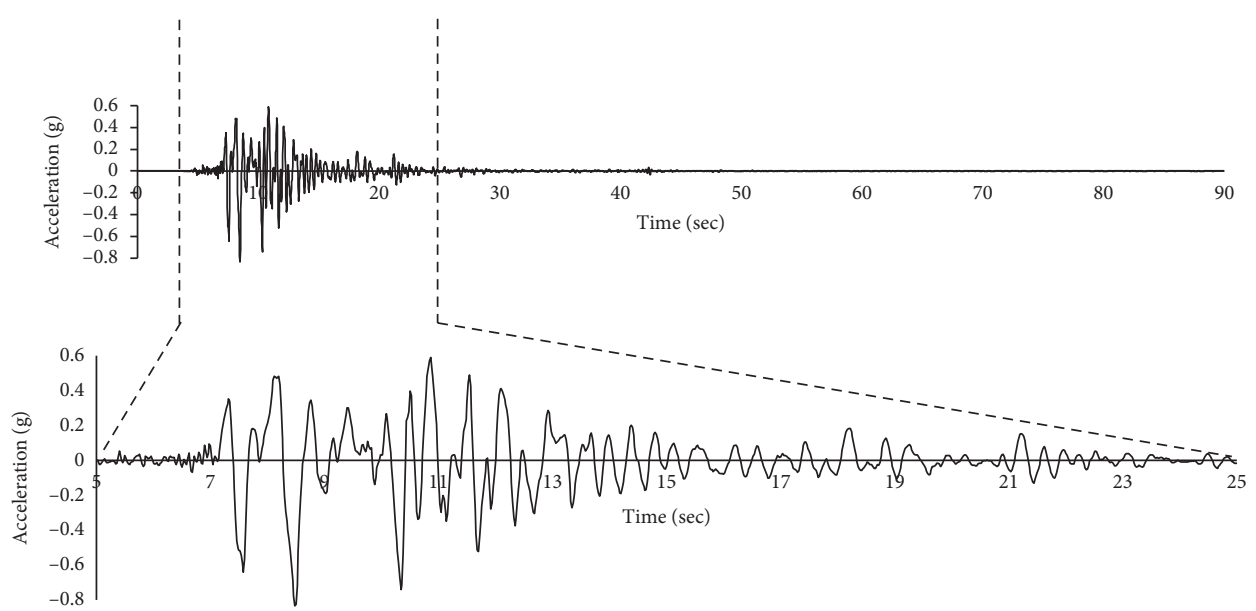

(a)

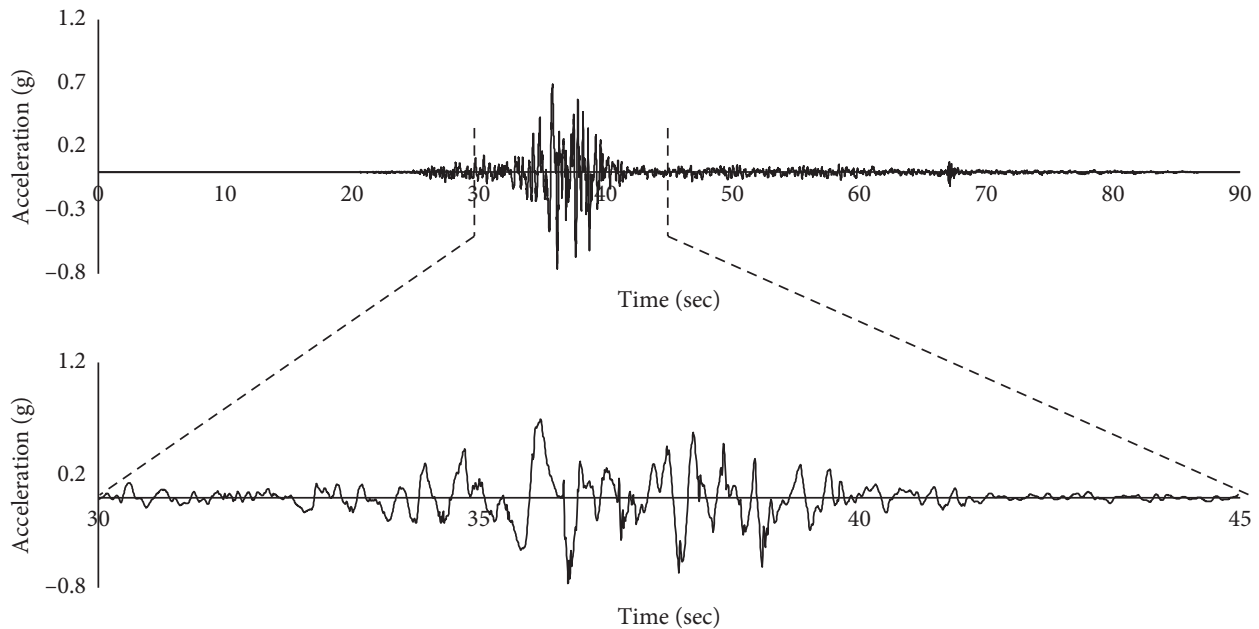

(b)

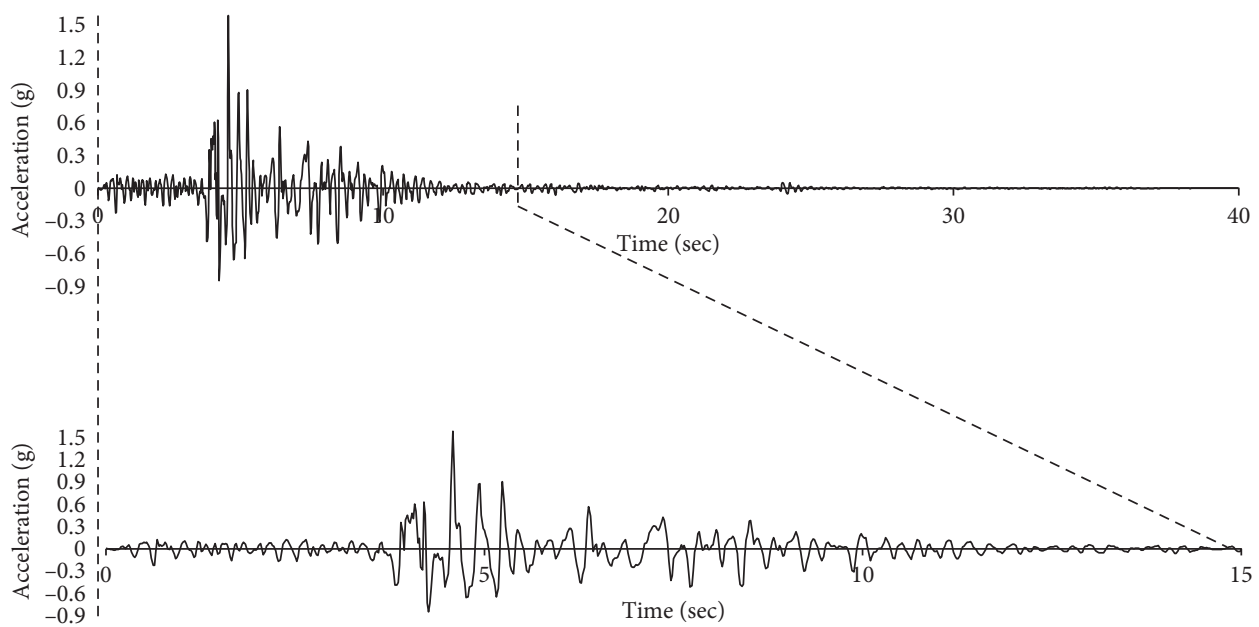

(c)

Figure 13: (a) Original and reduced 1995 Kobe earthquake ground motion. (b) Original and reduced 1999 Chi-Chi earthquake ground motion. (c) Original and reduced 1994 Northridge earthquake ground motion.

webs of the box girder showed excessive cracks. At 7.25 seconds, the web of the right box girder failed mainly in shear. At 8 seconds, the right bay of the box girder hit the ground. At the 15th second, the left box girder initiated failure in shear and settled on the ground. At analysis 


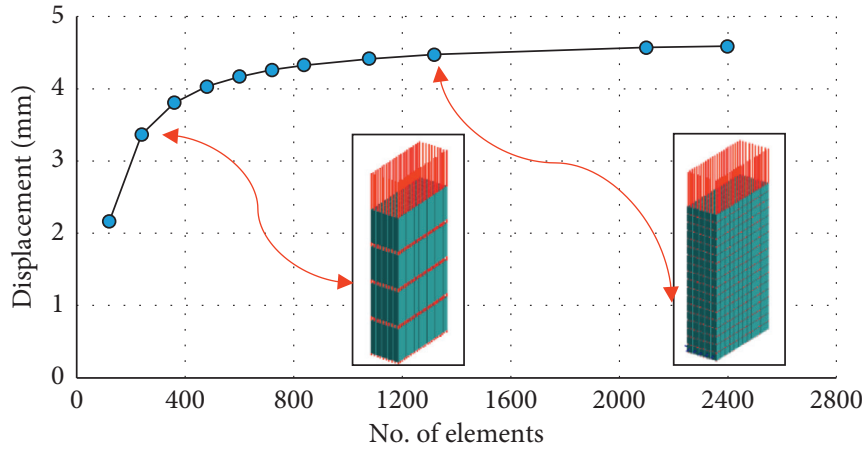

(a)

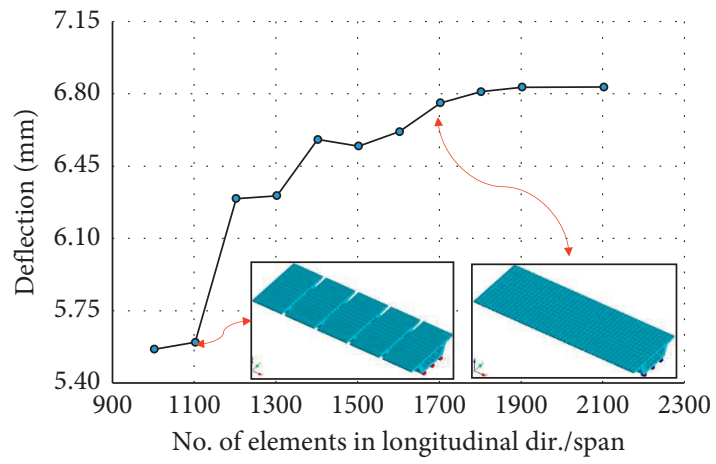

(b)

FIgURE 14: Mesh sensitivity of the column and the box girder. (a) Column. (b) Box girder.

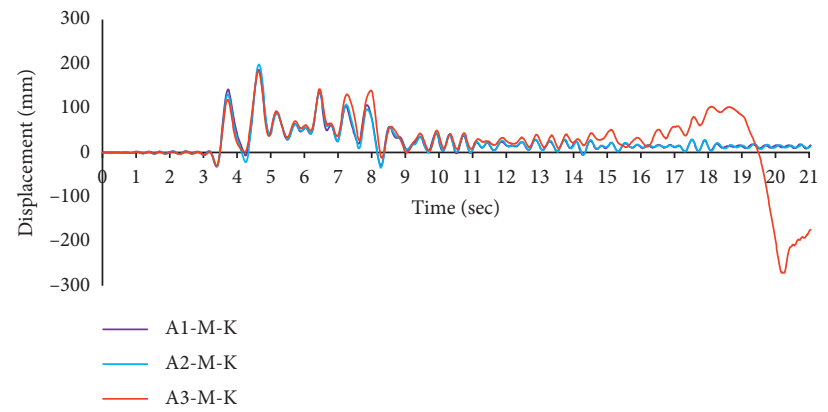

FIGURE 15: Displacements-time history of the right column of models "A1-M-K, A2-M-K, and A3-M-K."

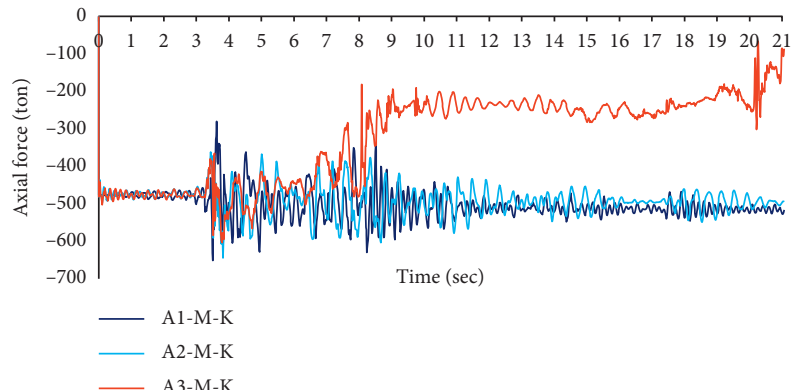

(a)

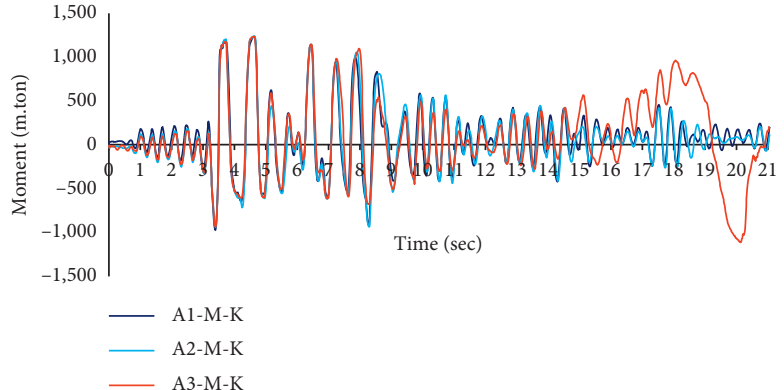

(b)

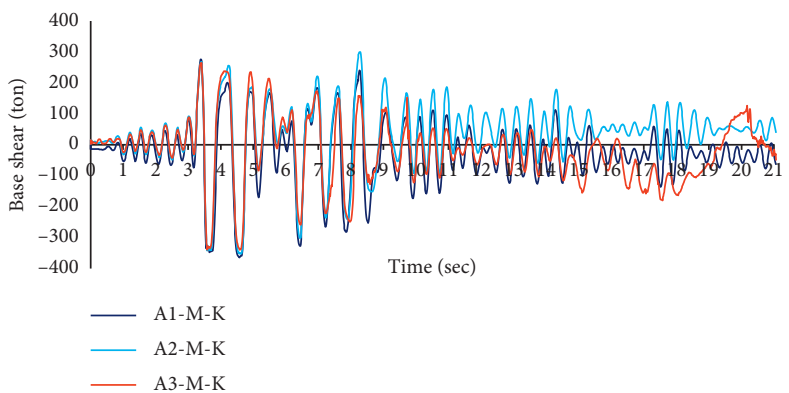

(c)

Figure 16: (a) Axial force-time history of the right column of models "A1-M-K, A2-M-K, and A3-M-K." (b) Moment-time history of the right column of models "A1-M-K, A2-M-K, and A3-M-K." (c) Base shear-time history of the right column of models "A1-M-K, A2-M-K, and A3-M-K." 


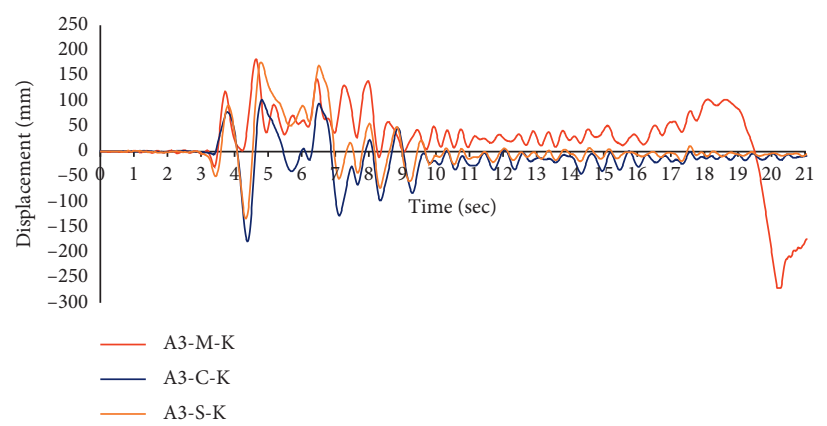

Figure 17: Displacements-time history of the right column of models "A3-M-K, A3-C-K, and A3-S-K."
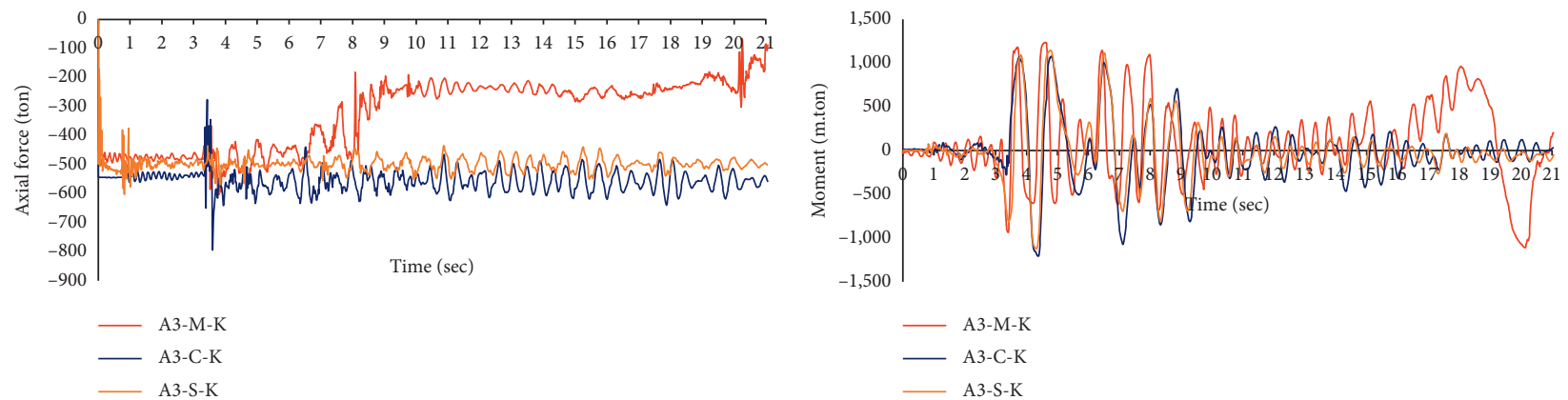

(a)

(b)

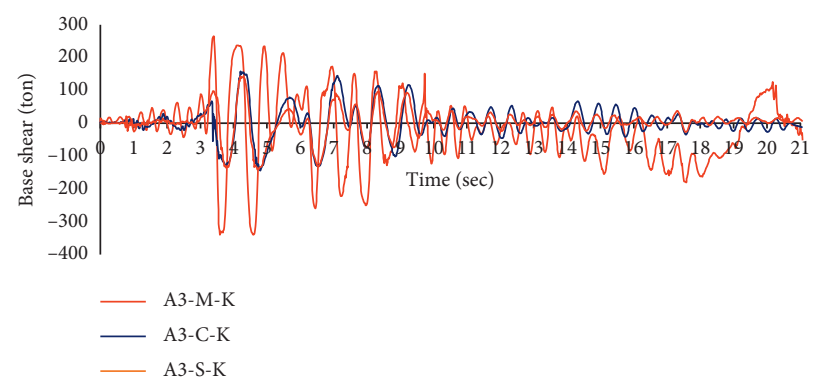

(c)

Figure 18: (a) Axial force-time history of the right column of models "A3-M-K, A3-C-K, and A3-S-K." (b) Moment-time history of the right column of models "A3-M-K, A3-C-K, and A3-S-K." (c) Base shear-time history of the right column of models "A3-M-K, A3-C-K, and A3-S-K."

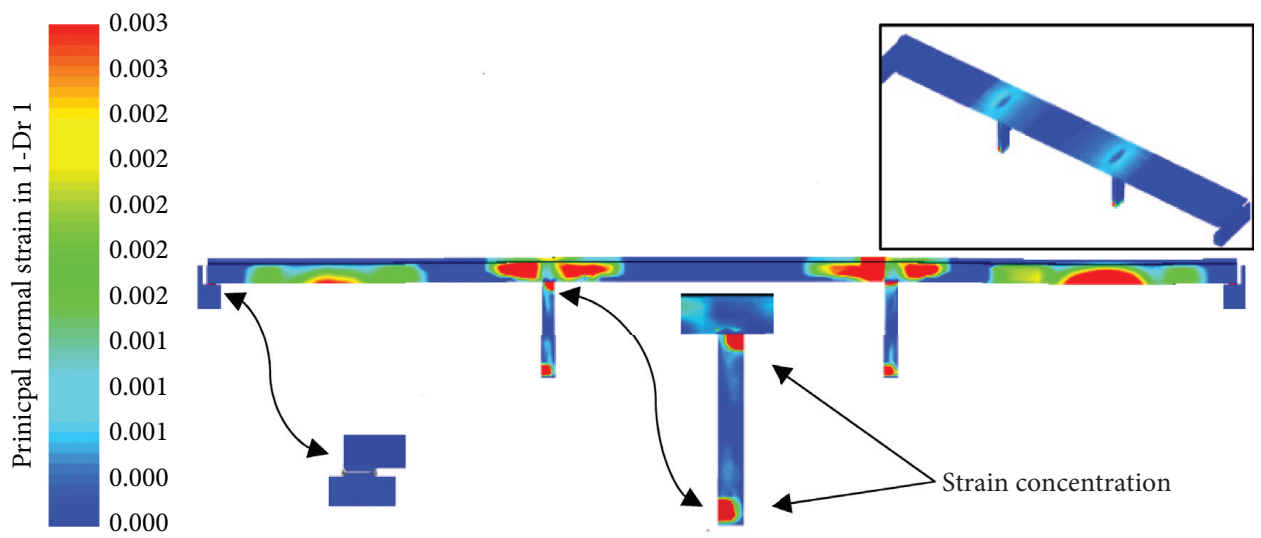

Figure 19: Principal normal strain of model "A1-M-K." 


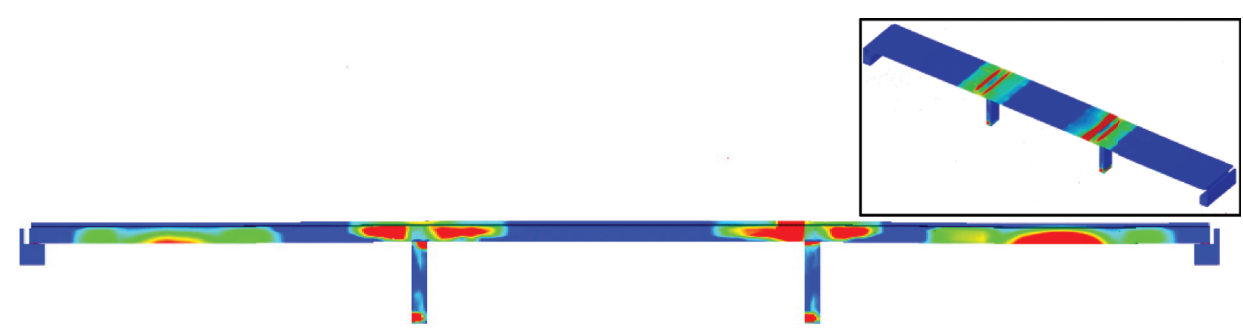

Figure 20: Principal normal strain of model "A2-M-K."

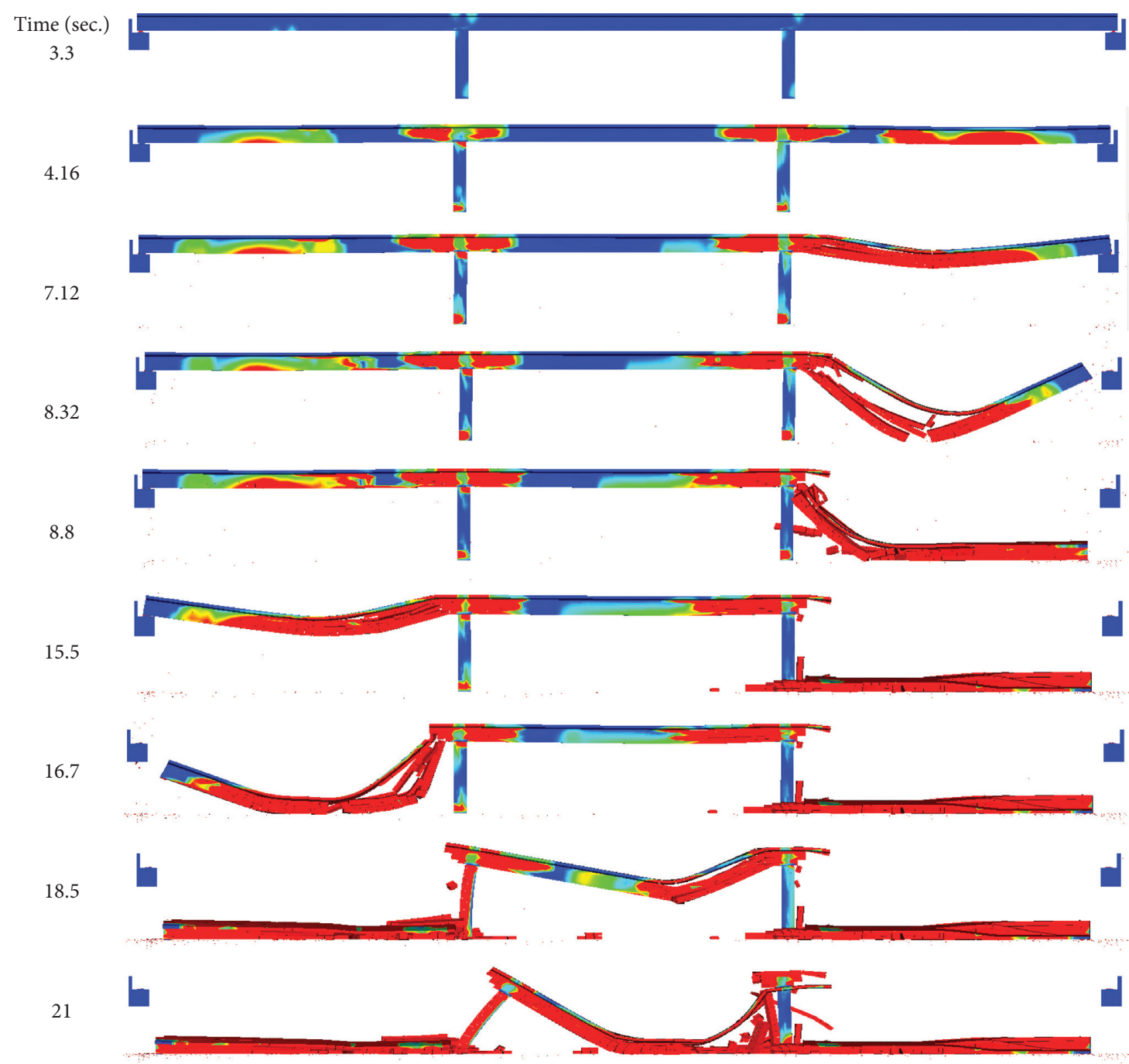

(a)

Figure 21: Continued. 

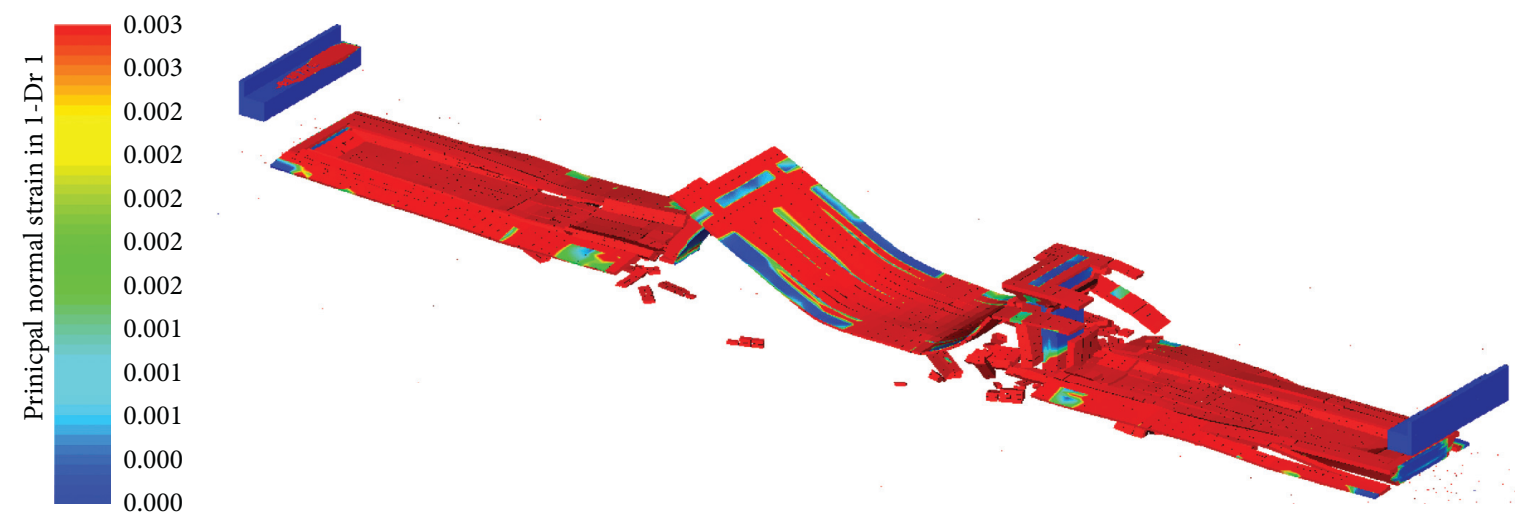

(b)

FigURE 21: (a) 2D view of the principal normal strain during the time history "model A3-M-K." (b) 3D view of the principal normal strain during the time history "model A3-M-K."

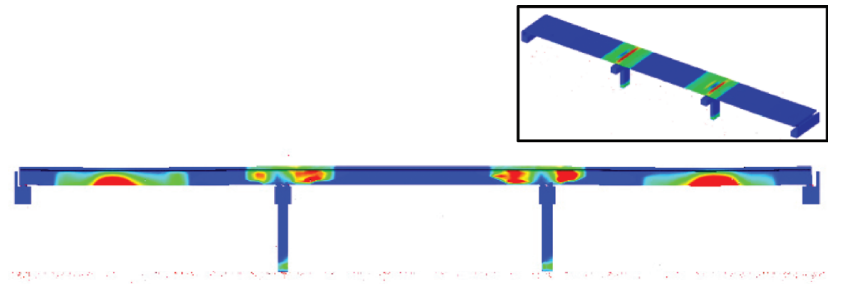

Figure 22: Principal normal strain during the time of "model A3-C-K."

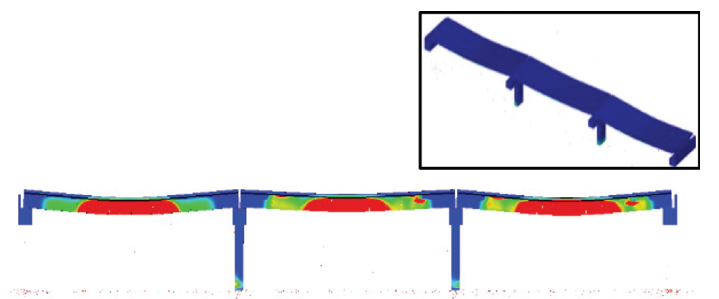

FIgURE 23: Principal normal strain during the time of "model A3-S-K."

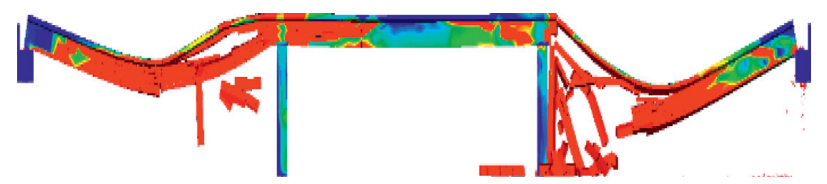

Figure 24: Principal normal strain at the end of the analysis, "model A3-M-C."

termination reaching the 20 th second, the middle bay failed, and the bay weight dragged the left column down.

In the monolithic bridge models, the seismic ground motions brought about cracks at the upper and lower ends of the columns in the plastic hinge zones, since they are the areas of stress concentration. It should be noted that the cracks did not spread along with the column height, as the column dimensions were very large $(1 \times 2.5$ meters $)$, and the amount of reinforcing steel, either stirrups or longitudinal reinforcement, was very high. Also, in Figure 21, at the end of the seismic analysis, the middle bay of the box girder collapsed and dragged the left column down to the ground and the left column showed large strain values along with its height.

Figures 22 and 23 show principal normal strain during the time of models $\mathrm{A} 3-\mathrm{C}-\mathrm{K}$ and $\mathrm{A} 3-\mathrm{S}-\mathrm{K}$, respectively. Models $\mathrm{A} 3-\mathrm{C}-\mathrm{K}$ and $\mathrm{A} 3-\mathrm{S}-\mathrm{K}$ did not show any collapse behavior even though they contain the same reinforcement amount as model A3-M-K. The reason is that the less the internal restrains in the bridge, a decrease in collapse possibility takes place. Also, the columns did not show enough strain values as the tops of these columns are free to move and they are not constrained with the bridge superstructure. 


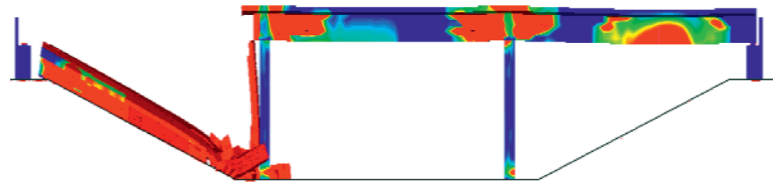

FIgURe 25: Principal normal strain at the end of the analysis, "model A3-M-N."

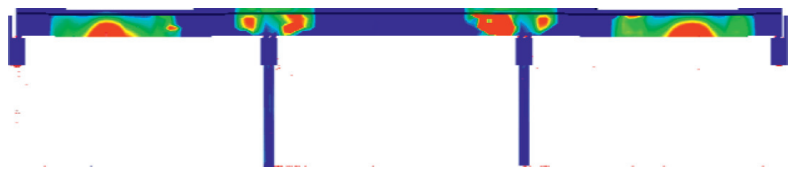

FIgURE 26: Principal normal strain at the end of the analysis, "model A3-C-C."

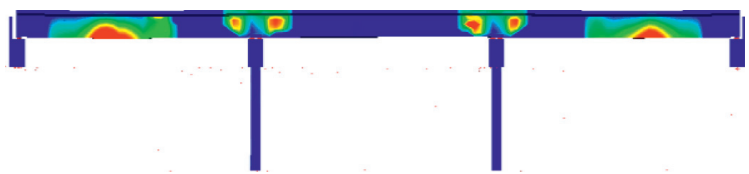

Figure 27: Principal normal strain at the end of the analysis, "model A3-C-N."

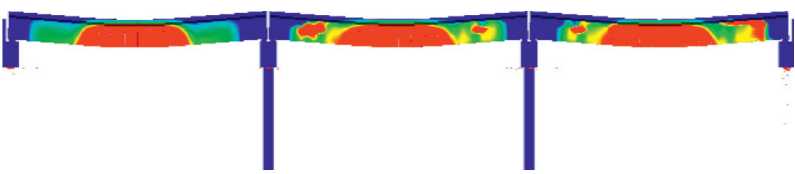

Figure 28: Principal normal strain at the end of the analysis, model "A3-S-C."

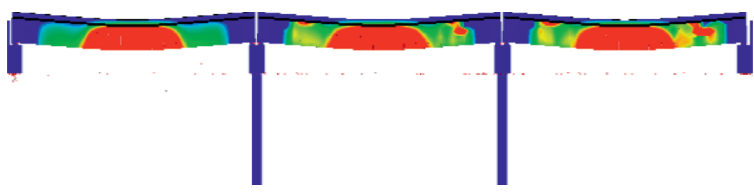

FIgUre 29: Principal normal strain at the end of the analysis, model "A3-S-N."

9.4. Collapse Analysis of the Different Bridge Models under Different Severe Ground Motions. Kobe, Chi-Chi, and Northridge ground motions were used to analyze monolithic, simple, and continuous bridge models to determine the effect of severe ground motions on the collapse behavior of these bridge models. From models A3-M-K, A3-M-C, and A3-M-N, it is noted that the monolithic bridge model always had a collapse behavior once the reinforcement ratio of the superstructure has been reduced below the minimum reinforcement ratio (Figures 21, 24, and 25) On the other hand, when analyzing simple and continuous on bearing bridge models with the minimum reinforcement ratios by using the different ground motions, they did not show any collapse behavior (Figures 22, 23, and 26-29).

In model A3-M-K, it is noted that the monolithic bridge model collapsed by Kobe ground acceleration, while by analyzing the same bridge configuration it showed a partial collapse by Chi-Chi and Northridge ground accelerations, as in models A3-M-C and A3-M-N. Thus, the collapse of the structures did not depend on the largest value of the peak ground acceleration; yet it depended on the number of cyclic reversal accelerations.

\section{Conclusions}

In the current study, the seismic progressive collapse behavior and analysis of reinforced concrete bridges were analyzed. Various bridge configurations: monolithic with columns, continuous on bearings, and simple on bearings bridge models were analyzed. The bridge models and selected earthquake excitations used in the study were discussed. A summary of the findings is presented herein.

(i) Progressive collapse will not occur unless the reinforcement ratio of the bridge superstructure is reduced to the minimum reinforcement ratio according to the ECP 203-2018.

(ii) Monolithic bridge models with reduced reinforcement ratio always show a collapse behavior during the analysis using severe ground motions. 
However, changing the bridge structural system from monolithic to continuous or simple on bearing bridge models prevented the bridge models from collapse.

(iii) The total collapse of the structures does not depend on the largest value of the peak ground acceleration as in Northridge, and it depends on the number of reversal cycles of reversal waves as in Kobe.

(iv) In reinforced bridge models that are designed according to "The Egyptian Code of Practice 2032018," the reinforcement ratio in the bridge prevents any bridges from collapsing even under the influence of the severe ground motions, but it may show some cracks both at the bridge superstructure and at the column bases.

(v) Similar progressive collapse phenomenon is observed in the collapse of bridge structures caused by blast or abnormal loads and is also observed in the failures of structures during earthquakes even although the damage and propagation characteristics are more universal in nature, as can be detected in the analysis and simulation results in this study.

(vi) ELS program can be a means to predict the behavior of ordinary and special structures against abnormal events during the design, construction, and service loads.

(vii) Sufficient ductility capacity in bridge columns or piers can help ensure ductile behavior and higher deformation capability of the structure that leads to better performance against seismic progressive collapse.

\section{Data Availability}

The datasets used to support the findings of this study are incorporated into the article.

\section{Conflicts of Interest}

The authors declare that that there are no conflicts of interest regarding the publication of this paper.

\section{References}

[1] T. Krauthammer, L. Robert, S. C. W. Hall, T. B. James, and R. H. John, "Development of progressive collapse analysis procedure and condition assessment for structures," Protective Technology Center, The Pennsylvania University, Philadelphia, PA, USA, 2002.

[2] U. Starossek, "Progressive collapse of structures: nomenclature and procedures," Structural Engineering International, vol. 16, no. 2, pp. 113-117, 2006.

[3] F. Seible, G. Hegemier, V. M. Karbhari et al., "Protection of our bridge infrastructure against man-made and natural hazards," Structure and Infrastructure Engineering, vol. 4, no. 6, pp. 415-429, 2008.

[4] W. G. Corley, "Applicability of seismic design in mitigating progressive collapse," in Proceedings of the National Workshop on Prevention of Progressive Collapse, p. 13, Multi-Hazard
Mitigation Council of the National Institute of Building Sciences, Rosemont, IL, USA, July 2002.

[5] J. R. Hayes Jr., S. C. Woodson, R. G. Pekelnicky, C. D. Poland, W. G. Corley, and M. Sozen, "Can strengthening for earthquake improve blast and progressive collapse resistance," Journal of Structural Engineering, vol. 131, no. 8, pp. 11571177, 2005.

[6] C. Gurley, "Progressive collapse and earthquake resistance," Practice Periodical on Structural Design and Construction, vol. 13, no. 1, pp. 19-23, 2008.

[7] H. Wibowo, S. S. Reshotkina, and D. T. Lau, "Modeling progressive collapse of RC bridges during earthquakes," in Proceedings of the CSCE Annual General Conference 2009: On the Leading Edge, p. 11, St. John's, NL, Canada, May 2009.

[8] J. Guedes, Seismic behavior of reinforced concrete bridges: modelling, numerical analysis, and experimental assessment, Ph.D. thesis, Department of Civil Engineering, University of Porto, Porto, Portugal, 1997.

[9] H. Salem, S. Mohssen, Y. Nishikiori, and A. Hosoda, "Numerical collapse analysis of Tsuyagawa bridge damaged by Tohoku tsunami," Journal of Performance of Constructed Facilities, vol. 30, no. 6, Article ID 04016065, 2016.

[10] M. Domaneschi, C. Pellecchia, E. De Iuliis et al., "Collapse analysis of the Polcevera viaduct by the applied element method," Engineering Structures, vol. 214, p. 110659, 2020.

[11] ASI (Applied Science International), "Extreme loading for structures 3.1," 2018, http://www.appliedscienceint.com/ extreme-loading-forstructures/.

[12] H. Tagel-Din and K. Meguro, "Applied element method for dynamic large deformation analysis of structures," Structural Engineering/Earthquake Engineering-International Journal of the Japan Society of Civil Engineers, vol. 17, no. 2, pp. 215-224, 2000.

[13] H. Tagel-Din and K. Meguro, "Applied element method for simulation of nonlinear materials: theory and application for RC structures," Structural Engineering/Earthquake Engineering-International Journal of the Japan Society of Civil Engineers, vol. 17, no. 2, pp. 123s-148s, 2000.

[14] K. Bathe, Solution of Equilibrium Equations in Dynamic Analysis, Prentice-Hall, Englewoods Cliffs, NJ, USA, 1995.

[15] A. Chopra, Dynamics of Structures: Theory and Applications to Earthquake Engineering, Prentice-Hall, Englewood Cliffs, NJ, USA, 1995.

[16] K. Maekawa and H. Okamura, "The deformational behavior and constitutive equation of concrete using the elastoplastic and fracture model," Journal of Faculty Engineering University of Tokyo (B), vol. 37, no. 2, pp. 253-328, 1983.

[17] H. Okamura and M. Kohichi, Nonlinear Analysis and Constitutive Models of Reinforced Concrete, Giho-do Press, Tokyo, Japan, 1991.

[18] D. Ristic, "Stress-strain based modeling of hysteretic structures under earthquake-induced bending and varying axial loads," Research Report No. 86-ST-01, School of Civil Engineering, Kyoto University, Kyoto, Japan, 1986.

[19] C. Chiara and P. Rui, "Seismic response of continuous span bridges through fiber-based finite element analysis," Earthquake Engineering and Engineering Vibration, vol. 5, no. 1, pp. 119-131, 2006.

[20] D. T. Lau and H. Wibowo, "Seismic progressive collapse analysis of reinforced concrete bridges by applied element method," in Proceedings of the Earth and Space, Honolulu, Hi, USA, March 2010.

[21] A. Seyedkhoei, R. Akbari, and S. Maalek, "Earthquake-Induced domino-type progressive collapse in regular, 
semiregular, and irregular bridges," Shock and Vibration, vol. 2019, Article ID 8348596, 18 pages, 2019.

[22] C. Akogul and O. Celik, "Effect of elastomeric bearing modeling parameters on the seismic design of RC highway bridges with precast concrete girders," in Proceedings of the 14th World Conference on Earthquake Engineering (14WCEE), Beijing, China, October 2008.

[23] W.-F. Chen and L. Duan, Bridge Engineering Handbook, CRC Press, Boca Raton, FL, USA, 2014.

[24] S. Malek, R. Akubari, and S. Ziaei-Rad, "Estimation of elastomeric bridge bearing shear modulus using operational modal analysis," in Proceedings of the 2nd International Operational Modal Analysis Conference, IOMAC, Copenhagen, Denmark, May 2007.

[25] D. Mitchell, M. Bruneau, M. Saatcioglu, M. Williams, D. Anderson, and R. Sexsmith, "Performance of bridges in the 1994 Northridge earthquake," Canadian Journal of Civil Engineering, vol. 22, no. 2, pp. 415-427, 1995.

[26] D. L. Anderson, D. Mitchell, and R. G. Tinawi, "Performance of concrete bridges during the Hyogo-ken nanbu (Kobe) earthquake on January 17, 1995," Canadian Journal of Civil Engineering, vol. 23, no. 3, pp. 714-726, 1996.

[27] K. Kawashima, "Seismic performance of RC bridge piers in Japan: an evaluation after the 1995 Hyogo-ken nanbu earthquake," Progress in Structural Engineering and Materials, vol. 2, no. 1, pp. 82-91, 2000.

[28] J. W. Wallace, M. O. Eberhard, S.-J. Hwang et al., "Highway bridges," Earthquake Spectra: Chi-Chi Earthquake Reconnaissance Report, vol. 17, no. SI, pp. 131-152, 2001.

[29] Y. T. Hsu and C. C. Fu, "Seismic effect on highway bridges in Chi Chi earthquake," Journal of Performance of Constructed Facilities, vol. 18, no. 1, pp. 47-53, 2004.

[30] PEER Ground Motion Database-PEER Center, Ngawest2.berkeley.edu, 2020, https://ngawest2.berkeley.edu/ spectras/191246/searches/176626/edit.

[31] ECP 203-2018, "The Egyptian Code for Design and Construction of Concrete Structures," Ministry of Housing, Utilities and Urban Development, Cairo, Egypt, 2018. 